\title{
Provincial legislative and regulatory standards for pain assessment and management in long-term care homes: a scoping review and in-depth case analysis
}

Natasha L. Gallant ${ }^{1}$, Allie Peckham²,3, Gregory Marchildon ${ }^{3^{*}}$, Thomas Hadjistavropoulos ${ }^{1}$, Blair Roblin ${ }^{3}$ and Rhonda J. N. Stopyn ${ }^{1}$

\begin{abstract}
Background: Among Canadian residents living in long-term care (LTC) facilities, and especially among those with limited ability to communicate due to dementia, pain remains underassessed and undermanaged. Although evidence-based clinical guidelines for the assessment and management of pain exist, these clinical guidelines are not widely implemented in LTC facilities. A relatively unexplored avenue for change is the influence that statutes and regulations could exert on pain practices within LTC. This review is therefore aimed at identifying the current landscape of policy levers used across Canada to assess and manage pain among LTC residents and to evaluate the extent to which they are concordant with evidence-based clinical guidelines proposed by an international consensus group consisting of both geriatric pain and public policy experts.
\end{abstract}

Methods: Using scoping review methodology, a search for peer-reviewed journal articles and government documents pertaining to pain in Canadian LTC facilities was carried out. This scoping review was complemented by an in-depth case analysis of Alberta, Saskatchewan, and Ontario statutes and regulations.

Results: Across provinces, pain was highly prevalent and was associated with adverse consequences among LTC residents. The considerable benefits of using a standardized pain assessment protocol, along with the barriers in implementing such a protocol, were identified. For most provinces, pain assessment and management in LTC residents was not specifically addressed in their statutes or regulations. In Alberta, Saskatchewan, and Ontario, regulations mandate the use of the interRAl suite of assessment tools for the assessment and reporting of pain.

\footnotetext{
* Correspondence: Greg.Marchildon@utoronto.ca

${ }^{3}$ Institute of Health Policy, Management and Evaluation, University of Toronto, 425-155 College Street, Toronto, Ontario M5T 3M6, Canada

Full list of author information is available at the end of the article
}

(c) The Author(s). 2020 Open Access This article is licensed under a Creative Commons Attribution 4.0 International License, which permits use, sharing, adaptation, distribution and reproduction in any medium or format, as long as you give appropriate credit to the original author(s) and the source, provide a link to the Creative Commons licence, and indicate if changes were made. The images or other third party material in this article are included in the article's Creative Commons licence, unless indicated otherwise in a credit line to the material. If material is not included in the article's Creative Commons licence and your intended use is not permitted by statutory regulation or exceeds the permitted use, you will need to obtain permission directly from the copyright holder. To view a copy of this licence, visit http://creativecommons.org/licenses/by/4.0/. The Creative Commons Public Domain Dedication waiver (http://creativecommons.org/publicdomain/zero/1.0/) applies to the data made available in this article, unless otherwise stated in a credit line to the data. 


\begin{abstract}
(Continued from previous page)
Conclusion: The prevalence of pain and the benefits of implementing standardized pain assessment protocols has been reported in the research literature. Despite occasional references to pain, however, existing regulations do not recommend assessments of pain at the frequency specified by experts. Insufficient direction on the use of specialized pain assessment tools (especially in the case of those with limited ability to communicate) that minimize reliance on subjective judgements was also identified in current regulations. Existing policies therefore fail to adequately address the underassessment and undermanagement of pain in older adults residing in LTC facilities in ways that are aligned with expert consensus.
\end{abstract}

Keywords: Canada, Long-term care, Pain assessment, Pain management, Quality standards

\section{Background}

\section{Pain assessment \& management}

The underassessment and undermanagement of pain in older adults, and especially those with dementia, residing in long-term care (LTC) facilities has been identified as an increasingly important issue [1]. First, pain is highly prevalent among older adults in LTC facilities [2]. In fact, pain has been documented as being more common than any other chronic condition in LTC [3]. Second, the underassessment of pain in this population is welldocumented [4]. It has been demonstrated, for instance, that treating physicians were not able to detect pain in $34 \%$ of LTC residents known to be suffering from pain [5]. Importantly, inadequate pain assessments can result in unnecessary suffering and missed opportunities for early intervention among LTC residents [6, 7]. Third, considerable evidence suggests that seniors in LTC are undertreated for pain [8-11]. Unsurprisingly, the undermanagement of pain in LTC is most significant for persons with cognitive impairments and limited ability to communicate $[12,13]$. The undermanagement of pain in is also of concern given that unmanaged pain in this population is associated with decreased socialization [14], exacerbated symptoms of dementia [10], worsened mood and depression $[15,16]$, as well as increased care needs and costs at the organizational level [10].

Adequate assessment and management of pain are therefore necessary if we are to improve health status, quality of life, and satisfaction of residents as well as their family members and care team $[5,17]$. Researchers, practitioners, and decision makers who support a rapidly aging population recognize the importance of the underassessment and undermanagement of pain in LTC [1820]. Internationally, several clinical guidelines have been developed for pain assessment and management in LTC [14, 21-29]. Observational assessment tools that are specialized, validated, and easy-to-use have been made available (e.g. [30],); practical approaches to assessment have been articulated (e.g., assess pain before and after an analgesic trial, consult with collaborative informants [31];); and minimum frequencies for pain assessment in LTC have been recommended [32]. Furthermore, many clinical guidelines on pain assessment in LTC emphasize the need to use specialized observational tools that have been developed for the assessment of pain [e.g., 22, 28].

Despite their development and availability, however, such approaches and protocols are not widely implemented in LTC practice. To gain a better understanding of this issue, a group of geriatric pain and public policy experts set out to examine the reasons behind the inadequate implementation of interventions to facilitate pain assessment and management in LTC [32]. They concluded that lack of satisfactory implementation of preexisting guidelines was the result of excessive demands placed on and limited resources available to LTC staff. As a response to this finding, clinical guidelines comprising of minimum standards that were thought to be feasible and appropriate for managing pain in LTC were articulated [32]: (1) all LTC residents must be assessed for pain on admission and at least once a week thereafter with some residents requiring more frequent assessments; (2) a treatment plan must be documented within $24 \mathrm{~h}$ of pain problem identification with reassessment of outcomes and side effects within another $24 \mathrm{~h}$; and (3) these assessments must involve a well-validated standardized assessment tool and, for residents unable to self-report pain, observational tools should be used.

To examine the desirability, validity, and feasibility of these guidelines, Hadjistavropoulos and colleagues surveyed administrators and front-line staff working in LTC across three Canadian provinces [32]. The results of this survey supported the proposed guidelines. That is, most participants reported that the guidelines were both highly desirable and feasible. Moreover, recent research suggests that the frequency of pain assessments can be successfully increased with the implementation of such systematic pain assessment practices in LTC facilities [33]. This increase in pain assessments was accomplished, for example, by dividing the task of pain assessments across front-line LTC staff to avoid an increase in workload among a select subgroup of staff members. It is important to find ways of improving the frequency of pain assessments in LTC environments as these improvements have been associated with reductions in 
polypharmacy and better pain management for residents as well as reduced job stress and burnout for staff [33, 34].

\section{Provincial Legislative \& Regulatory Standards}

Another reason for the lack of widespread implementation of standardized pain assessment and management protocols in LTC practice may be insufficient statutes and regulations that would facilitate their implementation. The use of public policy levers has previously been shown to be an essential component in achieving change within LTC settings. For example, the enactment of the 1987 Omnibus Budget Reconciliation Act in the United States resulted in a reduction in the use of unnecessary psychotropic medications in LTC facilities [35-37]. Thus, in a similar manner, increased attention needs to be placed on the public policy levers capable of facilitating the successful implementation of approaches and protocols to pain assessment and management within the Canadian context.

Regulatory instruments are among the most powerful tools at any government's disposal [38]. Such regulatory instruments take on two very different forms: One is a law that must be passed by a legislature in the full glare of the public eye, including media scrutiny, and the other is a regulation that is enacted by the executive branch of government with very limited public scrutiny. A statute is a written law, enacted by a provincial legislature either commanding or prohibiting some action or declaring a policy. A regulation sets out the details of how the statute will be applied and enforced.

In Canada, the authority to prescribe regulations is often governed, first, by general statutory enactments and, second, by the enabling Act. For example, Ontario's Interpretation Act states the general principle (s.23) that the "Lieutenant Governor in Council [i.e., cabinet] may make regulations for the due enforcement and carrying into effect of any Act of the Legislature" and the Regulations Act states (s.10) that "the Lieutenant Governor in Council may make regulations (b) prescribing the form, arrangement and scheme of regulations."

The statutes that govern LTC in each province go further to specify the scope of the regulations under those enabling Acts. To illustrate, the Ontario Long-Term Care Homes Act provides (s.38) that the Lieutenant Governor in Council (i.e., the provincial cabinet) may make regulations governing matters as broad as the mission statements of LTC homes (subsection 2(d)) and as narrow as the temperature requirements in each home (subsection 2(b)). In other words, the cabinet can make regulations without reference to the more involved process of all-party reviews by committees of the legislatures and the scrutiny of formal votes through provincial legislative assemblies.
All provincial governments have introduced statutes concerning the licensure, funding, operation, care, and inspection requirements of LTC homes and have provided for the promulgation of regulations to govern these matters [39, 40]. Most Canadian jurisdictions (with the exception of Prince Edward Island and Quebec) use the interRAI continuing care reporting system to input demographic, clinical, functional, and resource utilization data on individuals receiving continuing care in hospitals and LTC facilities across Canada. In recent years, these data have been collected using the interRAI-Minimum Data Set 2.0 (RAI-MDS 2.0 (e.g. [41, 42],). The RAI-MDS is a clinical assessment tool developed by interRAI, a not-forprofit collaboration of clinicians, researchers, and health administrators from over 30 countries committed to improving services for vulnerable populations such as older persons [43]. In Canada, the Canadian Institute of Health Information (CIHI) is responsible for collecting these data and publicly disseminating summary reports.

\section{Purpose}

This policy review was aimed at clarifying the Canadian statutes and regulations that support the appropriate assessment and management of pain in LTC and the extent to which these statutes and regulations are consistent with evidence-based clinical guidelines. To do so, a Canadian perspective on the way in which pain assessment and management approaches are embedded within quality standards in LTC facilities is provided with a more detailed focus on Alberta, Saskatchewan, and Ontario as provincial case studies.

\section{Methods}

Prior to completing the scoping review, preliminary searches for all Canadian jurisdictions were conducted to identify the statutes and regulations specific to pain assessment and management that governed LTC. Due to existing formal agreements with the relevant provincial ministries of health as well as reasons of expertise and feasibility, an in-depth case analysis of Alberta, Saskatchewan, and Ontario's statutes and regulations was conducted.

Given the exploratory nature of this study's research question, a scoping review using the stepwise approach outlined by Arksey and O'Malley (2005) was completed $[44,45]$. The purpose of this scoping review was to assess primary and secondary literature regarding legislative and regulatory standards related to assessing and managing pain among residents living in Canadian LTC facilities. To assess the primary literature, PubMed, Ovid, and ProQuest platforms were used to search databases such as PsycINFO, MEDLINE, EMBASE, ProQuest Dissertations \& Theses Global, Sociological Abstracts, Worldwide Political Science Abstracts, and Education 
Resources Information Centre. To assess the secondary literature, Canadian government documents were retrieved using the Canadian Research Index as well as custom Google searches. For both types of searches, the following search string was used to search the titles, abstracts, and keywords of each database or search engine: legislat* AND regulat* AND manag* AND quality standard" AND pain AND assess* AND (residential long-term care OR nursing home* OR long-term care home* OR facility based long-term care).

Once duplicates were removed, two reviewers screened titles and abstracts to determine if documents met the following criteria: (1) specific to the Canadian context; (2) focused on pain in LTC; (3) available as a full-text peerreviewed journal article or government document; (4) published on or after January 1, 2008; and (5) published in English. Each reviewer independently screened titles and abstracts of approximately half of the records identified and uncertainties about inclusion for records were resolved by consulting with the other reviewer to reach a consensus. Based on the screening of titles and abstracts, eligible full-text records were reviewed by the primary reviewer to determine inclusion in the review.

\section{Results}

\section{Scoping review}

For the scoping review, the original search was completed in June 2018 and an updated search was completed in June 2020. The searches resulted in 54,102 peer-reviewed journal articles and 40 government documents. Once duplicates were removed, titles and abstracts were screened, and full-text articles were reviewed, a total of 49 records were retained for this review (see Fig. 1).

\section{Primary literature}

A summary of pain-related data extracted from each of these peer-reviewed journal articles is provided in Table 1. Pain prevalence rates within Canadian LTC facilities ranged from 27.1 to $75.6 \%$, but it is important to note that methodological differences in definitions of pain, instruments used to measure pain, and populations examined existed [40, 51, 60, 64, 69]. Pain has also been shown to increase from admission to the end of residents' stay in LTC [47]. Among Canadian LTC residents, inadequately managed pain has been associated with interference in daily functioning, the onset of delirium, and increased transfers to hospital $[47,59,70]$.

Regular assessments using the PACSLAC, or other specialized pain assessment tools, can result in reduced pain, more frequent pain assessments, and improved pain management practices such as more appropriate prescribing of medications [6, 33, 34, 54]. Furthermore, nursing staff who regularly assess for pain using the PACSLAC reported lower stress and burnout levels as well as better communication with physicians [6, 34]. However, as previously mentioned, barriers in implementing standardized pain assessment protocols in LTC have been identified: time constraints, heavy workload, lack of resources, resistance to change by nursing staff, lack of management support, communication breakdown across professions, and communication difficulties between residents and nursing staff regarding pain [33, $48,49,53]$.

Solutions in addressing these barriers have also been proposed. For example, pain assessment knowledge increases and, consequently, pain practices improve among nursing staff following in-person or video-based pain assessment training programs [48, 49]. Other suggestions for improving pain assessment and management practices in LTC include an increase of physiotherapists embedded within LTC facilities and implementing a virtual consultation service to communicate with specialist physicians working in pain medicine $[23,50]$. Finally, ineffective pain assessment and management practices has influenced the development of clinical guidelines in palliative care $[52,71]$ given the importance placed on appropriate end-of-life management of pain among residents in LTC facilities [60].

\section{Secondary literature}

Findings from the secondary literature included in this scoping review is summarized in Additional file 1: Appendix A. For each province, the relevant statutes and regulations along with a brief description of the organization and administration of LTC homes within the province are listed. The basic provisions related to resident care and any specific references to pain are also identified. For example, Newfoundland and Labrador has issued operational standards [72], which state that, (i) with respect to a patient's integrated care plan, performance measures are to include "baseline pain assessment" (Standard 1.2(9)) and, (ii) with respect to care of a dying resident, "pain assessment, management and relief are provided as required" (Standard 13.4). Similarly, New Brunswick has issued a standards manual [73] that requires LTC facilities (i) to continually assess, plan, design, and implement programs, and specifically includes a pain management program, and (ii) to provide inservice training on pain management for all employees. Nova Scotia's program requirements [74] specify that "residents have an interdisciplinary assessment of $[\ldots]$ pain and discomfort" within the first 2 weeks of admission and that "resident care protocols, based on current leading practices, are developed, implemented, monitored and regularly evaluated with particular emphasis on [...] pain." In most provinces, however, the word "pain" is not specifically mentioned in their regulations (e.g., British Columbia [75], Manitoba [76], Prince 


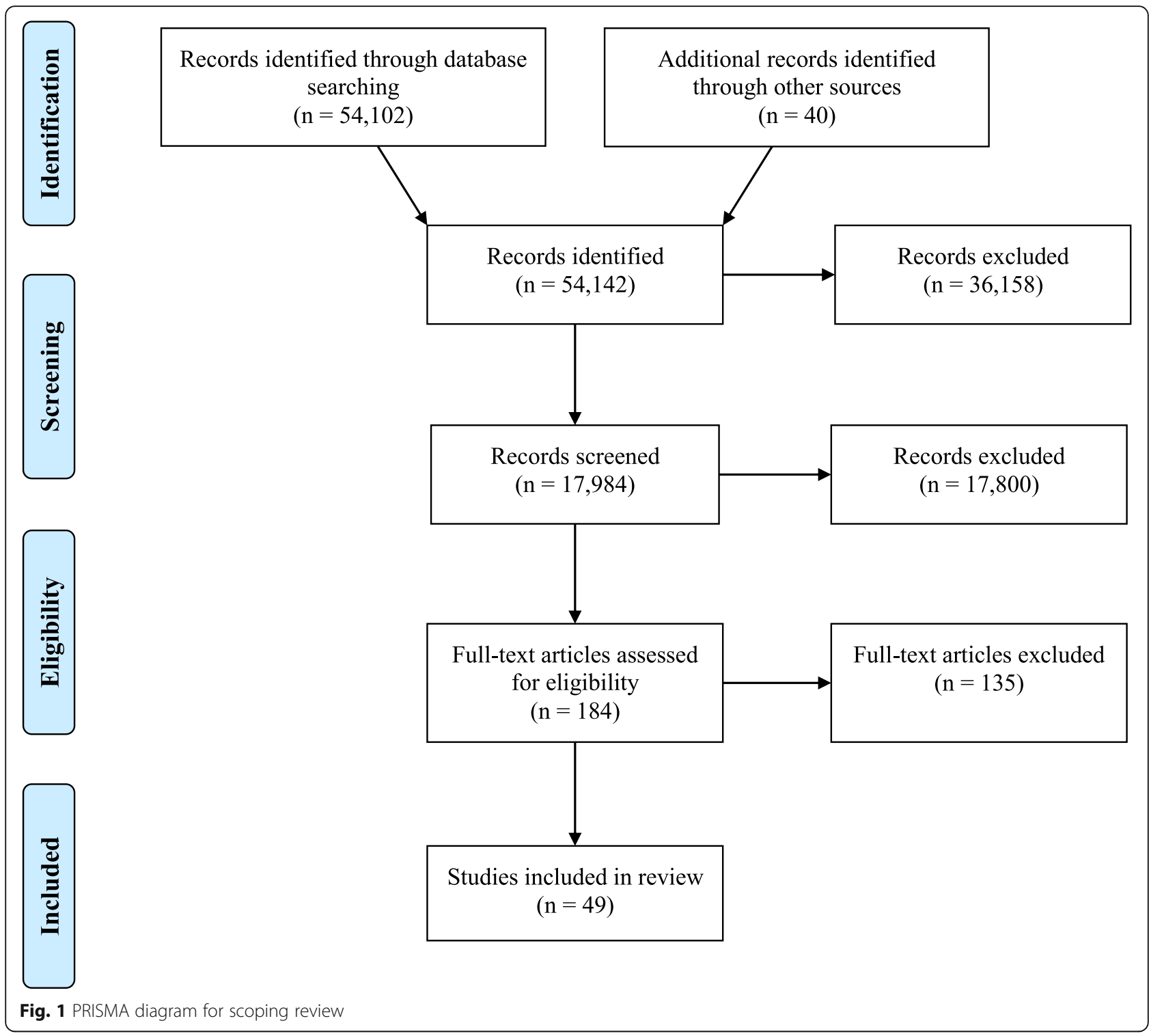

Edward Island [77]), although issues related to pain may be recognized and addressed in the context of the care assessment or plan that is typically the subject of regulatory provisions.

Nonetheless, measurement and quality indicators (e.g., RAI-MDS) are in place across Canada for assessing residents who may have pain [78, 79]. No standardized best practices for pain assessment and management, besides the administration of the RAIMDS as indicated above, however, exists in any Canadian jurisdiction. When using the RAI-MDS for the assessment of pain, clinicians are instructed to ask simple and direct questions about the experience of pain and to rely on self-report when possible. Other sources of information can include clinician observations or caregivers.
With regards to inspections, deterrence- or compliancebased approaches are used across jurisdictions. As an example, Ontario has been described as using a deterrencebased approach with prescribed and unannounced inspections [80]. Ontario also has public reporting of certain inspection results and offers a complex system of sanctionsfines, withholding funds, appointing temporary managers, and revoking licenses. Deterrence-based approaches to inspections are more effective as compliance-based approaches do not influence front-line staff making decisions that directly affect quality standards [81].

\section{In-depth case study of Alberta, Saskatchewan, and Ontario}

The in-depth case studies provided a more detailed examination of practice guidelines, protocols, and other 
Table 1 Overview of peer-reviewed journal articles identified for the scoping review

\begin{tabular}{lll}
\hline Reference & Jurisdiction & Brief Description of Methodology \\
\hline Bainbridge \& & Ontario & Bereaved caregivers $(N=1153)$ completed the \\
Seow (2018) [46] & & CaregiverVoice Survey
\end{tabular}

Cheung et al. Ontario

(2018) [47]

Estabrooks et al. Alberta, Saskatchewan (2013) [40] Ontario
Nursing staff regularly assessed residents with dementia using the PACSLAC $(N=89)$ or using a control measure $(N=84)$

LTC staff $(N=148)$ evaluated a pain assessment training video and completed pain-related measures

LTC staff $(N=131)$ participated in an in-person pain education program or a control education program

Review of clinical guidelines for pain assessment among LTC residents

Stakeholders $(N=168)$ completed a Stakeholder Feedback Questionnaire regarding the possibility of implementing pain-related guidelines

Medication administration in $\mathrm{LTC}$ residents $(N=$ 64) as well as interviews and focus groups with LTC staff $(N=19)$

Two LTC facilities evaluated by quality indicators for pain as well as interviews and focus groups with LTC staff $(N=34)$
Findings on Pain Assessment \& Management in LTC

- Caregivers rated the relief of physical pain for residents as excellent $(\sim 52.5 \%)$, very good $(\sim$ $7.5 \%)$, good $(\sim 22.5 \%)$, fair $(\sim 12.5 \%)$, and poor $(\sim$ $5 \%)$

- The proportion of residents reporting pain increased from baseline (42.3\%) to follow-up (49.7\%; $p<.001)$

- The presence of pain was significantly associated with the onset of delirium (OR: 1.64, $p<.001$ )

- $27.1 \%$ of LTC residents had daily pain

- Alberta showed higher rates of worsening pain compared to Saskatchewan and Manitoba

- Public facilities also had higher rates of worsening pain compared to private-for-profit and voluntary facilities

- Regular assessments using the PACSLAC resulted in improved pain management practices and reduced observable pain behaviours

- Nursing staff who regularly used the PACSLAC reported lower levels of stress and burnout

- Pain assessment knowledge increased after staff viewed the training video

- Staff thought positively about the content and quality of the training video

- Barriers to implementing pain practices demonstrated in the training video included time, workload, and resistance to change

- Pain knowledge, psychological beliefs about pain, and beliefs about pain and aging improved after staff participated in the education program

- Barriers to implementing pain practices suggested in the education program included difficult patient characteristics, time, resources, and communication breakdown across professions

- Only $4.2 \%$ of Canadian physiotherapists were working in LTC settings

- Physiotherapists can play a key role in assessing and managing pain among LTC residents

- Stakeholders from Saskatchewan believed the policy recommendation of implementing a multidisciplinary geriatrics team less feasible compared to stakeholders from British Columbia and Ontario

- Care aides rated the clinical recommendation of a documented treatment plan for residents with moderate-to-severe pain as more helpful compared to nurses

- Care aides rated the policy recommendation of implementing a multidisciplinary geriatrics team and of reporting on results using a consistent set of performance measures as more feasible than did nurses and administrators

- LTC residents who were a part of a pain assessment protocol were given fewer psychotropic medications than residents in the control group

- Protocol implementation resulted in more careful pain evaluation of LTC residents, better communication with physicians, and greater appropriate prescribing of medications

- Pain was assessed more frequently following implementation of pain assessment program

- Staff reported a positive impact following pain assessment program implementation and maintenance

- Implementation success was dependent on 
Table 1 Overview of peer-reviewed journal articles identified for the scoping review (Continued)

\begin{tabular}{llll}
\hline Reference & Jurisdiction & Brief Description of Methodology & Find \\
& & LTC
\end{tabular}

Findings on Pain Assessment \& Management in LTC

$\begin{array}{ll}\begin{array}{l}\text { Helmer-Smith } \\ \text { et al. (2020) [50] }\end{array} & \text { Ontario } \\ & \\ \text { Hill et al. (2019) } & \text { Alberta, Saskatchewan, } \\ \text { [71] } & \text { Manitoba, Ontario, Quebec }\end{array}$

Hirdes et al.

(2011) [51]

Hunter et al (2020) [52]

Kaasalainen et al. Ontario (2010) [53]

Yukon, British Columbia, Saskatchewan, Manitoba Ontario, Nova Scotia, Newfoundland \& Labrador

Alberta, Saskatchewan, Manitoba, Ontario

Kaasalainen et al. Canada (2016) [54]
eConsult cases $(N=24)$ by primary care providers in LTC and focus groups $(N=4)$ on eConsult use in LTC homes

Current national and provincial palliative care guiding documents $(N=25)$ management support and staff willingness - No changes in percentages of patients with moderate-to-severe pain

- Specialists (including Pain Medicine) reported benefits and feasibility of using the eConsult service

- Ineffective pain management was one of the clinical issues that stimulated the development of new guiding documents for palliative care

- The physical domain - which centers around pain and symptom management, maintaining cognition, and physical care-was addressed by $56 \%$ of guiding documents
Census data available from Statistics Canada's Canadian Socioeconomic Information Management system regarding $\mathrm{LTC}$ residents $(N=$ 128,168)

Professional and non-professional LTC staff ( $N=$ 228) completed a survey assessing qualities regarding palliative care

Interviews or focus groups were conducted with and survey was completed by pharmacists $(N=2)$, and physiotherapists $(N=2)$, administrators $(N=4)$, physicians $(N=4)$, care aides $(N=20)$, and nurses $(N=21)$

LTC residents $(N=345)$ participated in a pain management team led by a nurse practitioner, were led by a nurse practitioner without a pain management team, or had no nurse practitioner or pain management team
- Pain was commonly reported among LTC residents, such as 54.1 and $4.9 \%$ of residents in Saskatchewan who reported mild-to-moderate and excruciating pain, respectively

- LTC staff are likely ready to embrace a palliative care mandate as indicated by their emotional well-being

- Based on the survey, barriers to pain assessment included residents' limited ability to self-report their pain, residents' reluctance to report pain, and inadequate time for staff

- Based on interviews and focus groups, barriers were organized at the resident/family (e.g. residents' inability to communicate), healthcare provider (e.g. staff not believing residents' report of pain), and system (e.g., time constraints) levels

- Residents receiving care from the pain management team led by a nurse practitioner experienced reduced pain and improved functional status

- Clinical practice behaviours improved in the nurse-led pain management team

- Barriers to effective team functioning included lack of staff knowledge about medication management, establishing the role of the nurse practitioner on the team, and effectively communicating about residents' pain across staff

- Daily pain was not associated with greater disability at admission or over time

receiving disability assessments at admission and subsequent 2 years
LTC homes $(N=594)$ classified based on RAI-MDS quality indicators to predict performance

RAI-MDS 2.0 data on Complex Continuing Care $(N=2455)$ and $L T C$ residents $(N=142,386)$ who are comatose

Focus groups with LTC staff $(N=77)$ and family members of persons with dementia living in LTC $(N=19)$

- Quality indicator of worsening pain predicted the LTC homes needing improvement

- Lower proportion of residents who are comatose had documented pain compared to residents who are not comatose

- Staff and families thought that end-of-life pain management was critically important for residents

- Staff reported difficulties in assessing pain among residents with dementia

- Staff and families believed that pain assessment and management for residents with or without dementia were more accurate when they knew the resident well

Review of LTC resident charts and database notes $(N=748)$ from time periods

- Decisions to transfer LTC residents to hospital were influenced by inadequate pain control at the LTC as well as requests by family members or residents, inability to contact physician, injury, management and symptom control, and palliation

Data from LTC residents ( $N=2287)$ were obtained $\quad \cdot 37.9 \%$ of LTC residents reported experiencing from the data from the National Population 
Table 1 Overview of peer-reviewed journal articles identified for the scoping review (Continued)

\begin{tabular}{|c|c|c|c|}
\hline Reference & Jurisdiction & Brief Description of Methodology & $\begin{array}{l}\text { Findings on Pain Assessment \& Management in } \\
\text { LTC }\end{array}$ \\
\hline & & Health Survey & $\begin{array}{l}\text { rates of chronic pain than men } \\
\text { - Of LTC residents reporting chronic pain, reported } \\
\text { pain intensities were mild for } 22.4 \% \text {, moderate for } \\
50.0 \% \text {, and severe for } 27.6 \% \text { of residents } \\
\text { - Pain was found to interfere more with daily } \\
\text { activities for those LTC residents who reported } \\
\text { moderate or severe pain compared to those who } \\
\text { reported mild pain }\end{array}$ \\
\hline $\begin{array}{l}\text { Rosenberg et al. } \\
\text { (2019) [61] }\end{array}$ & British Columbia & $\begin{array}{l}\text { Individuals }(N=380) \text { receiving home-based pri- } \\
\text { mary geriatric care in the community assessed } \\
\text { using frailty and quality of life measures }\end{array}$ & $\begin{array}{l}\text { - Chronic pain did not predict transfer to LTC } \\
\text { facilities }\end{array}$ \\
\hline $\begin{array}{l}\text { Senderovich et al. } \\
\text { (2019) [62] }\end{array}$ & International & $\begin{array}{l}\text { Literature search on efficacy of herpes zoster } \\
\text { vaccine in LTC from } 2013 \text { to } 2018(N=10)\end{array}$ & $\begin{array}{l}\text { - Vaccine was associated with shorter pain duration } \\
\text { and reductions in pain severity }\end{array}$ \\
\hline $\begin{array}{l}\text { Tadrous et al. } \\
(2020)[63]\end{array}$ & Ontario & $\begin{array}{l}\text { LTC residents }(N=5363) \text { who were provided with } \\
\text { antipsychotics using academic detailing vs. usual } \\
\text { care }\end{array}$ & $\begin{array}{l}\text { - Residents who received academic detailing } \\
\text { reported a reduction in pain compared to those } \\
\text { who received usual care }\end{array}$ \\
\hline $\begin{array}{l}\text { Turcotte et al. } \\
\text { (2018) [64] }\end{array}$ & Ontario & $\begin{array}{l}\text { LTC residents with Alzheimer's disease or related } \\
\text { dementias }(N=107,381) \text { who were assessed using } \\
\text { the RAI-MDS } 2.0\end{array}$ & $\begin{array}{l}\text { - Of LTC residents with Alzheimer's disease and } \\
\text { related dementias, } 57.9 \% \text { reported no pain, 39.3\% } \\
\text { reported mild to moderate pain, and 2.8\% } \\
\text { reported excruciating pain }\end{array}$ \\
\hline $\begin{array}{l}\text { Watt-Watson et al. } \\
\text { (2013) [21] }\end{array}$ & Canada & $\begin{array}{l}\text { Documents were evaluated for entry-to-practice } \\
\text { competency requirements related to pain know- } \\
\text { ledge, skill, or judgment }(N=21)\end{array}$ & $\begin{array}{l}\text { - Pain-specific competencies were only listed for } \\
\text { dentistry }(N=2) \text {, nursing }(N=9) \text {, and veterinary } \\
(N=9) \text { documents }\end{array}$ \\
\hline $\begin{array}{l}\text { Wilchesky et al. } \\
\text { (2018) [65] }\end{array}$ & Quebec & $\begin{array}{l}\text { Medication intervention among residents with } \\
\text { severe dementia }(N=44)\end{array}$ & $\begin{array}{l}\text { - Slight increase in pain from pre-intervention (8.1) } \\
\text { to post follow up }(9.7, p<.0001) \text { but unclear if in- } \\
\text { crease is the result of intervention or disease } \\
\text { progression }\end{array}$ \\
\hline $\begin{array}{l}\text { Wilkinson et al. } \\
\text { (2019) [66] }\end{array}$ & Ontario & RAI-MDS 2.0 completed for LTC residents $(N=614)$ & $\begin{array}{l}\text { - Improvement in quality performance (including } \\
\text { pain management) over time in LTC homes from } \\
2012 \text { to } 2017\end{array}$ \\
\hline $\begin{array}{l}\text { Yoon et al. (2018) } \\
{[67]}\end{array}$ & $\begin{array}{l}\text { Alberta, Manitoba, Ontario, New } \\
\text { Brunswick }\end{array}$ & $\begin{array}{l}\text { LTC residents }(N=559) \text { received a standardized } \\
\text { oral health examination }\end{array}$ & $\begin{array}{l}\text { - Less than } 20 \% \text { of residents with dentures reported } \\
\text { pain in teeth or jaw pain but self-report may } \\
\text { underestimate prevalence }\end{array}$ \\
\hline $\begin{array}{l}\text { Yoon et al. (2020) } \\
{[68]}\end{array}$ & Alberta & $\begin{array}{l}\text { Nine focus groups with LTC staff }(N=44) \text { on } \\
\text { residents' oral and dental health }\end{array}$ & $\begin{array}{l}\text { - Staff primarily relied on resident self-reports of } \\
\text { mouth pain } \\
\text { - Pain was inferred from changes in eating and } \\
\text { non-verbal expressions of pain (i.e., facial } \\
\text { grimacing) }\end{array}$ \\
\hline $\begin{array}{l}\text { Yu et al. (2020) } \\
{[69]}\end{array}$ & Ontario & $\begin{array}{l}\text { Newly admitted LTC residents }(N=4853) \text { following } \\
\text { a stroke assessed for care needs and mortality }\end{array}$ & $\begin{array}{l}\text { - Female LTC residents more likely to have pain } \\
\text { compared to male LTC residents }\end{array}$ \\
\hline
\end{tabular}

authoritative standards required of practitioners involved in pain assessment and management in LTC facilities. Table 2 summarizes the results of the in-depth case analysis of Alberta, Saskatchewan, and Ontario as it pertains to pain assessment and management in LTC. As well, Table 2 includes pain-related interRAI indicators as reported by CIHI.

\section{Alberta}

In Alberta, the Ministry of Health is responsible for setting strategic direction; establishing legislation, policies, and provincial standards of health care; and measuring and reporting on quality and performance across the health system. LTC facilities are governed under the Nursing Homes Act, 2000. In addition to governing the terms of contracts, the Act lays out general terms for the operation of LTC homes. The Nursing Home General
Regulation under the Act defines basic care (section 2) as a wide variety of ancillary accommodation, meals, and personal services but does not mention pain assessment or management procedures. The Nursing Home Operation Regulation delineates the admission policies of nursing homes, resident assessments, staffing requirements and qualifications.

Alberta Health Services, directly accountable to the Minister of Health and Alberta Health (the Department of Health), is responsible for the delivery of health care in the province and for establishing operational policy. Subsection 4(2) of the Nursing Home General Regulation requires that LTC facility operators comply with two sets of standards set by the Alberta Health Services. The first is the Long-Term Care Accommodation Standards and Checklist, 2010 [41], which is set by Alberta Health's Standards Compliance and Licensing Branch 
Table 2 References to regulatory instruments and associated outcomes for pain in Alberta, Saskatchewan, and Ontario

\begin{tabular}{|c|c|c|c|c|c|}
\hline Province & $\begin{array}{l}\text { Specific regulatory instrument } \\
\text { for pain }\end{array}$ & $\begin{array}{l}\text { interRAI } \\
\text { instrument } \\
\text { mandated for } \\
\text { pain }\end{array}$ & $\begin{array}{l}\text { Experiencing Pain in } \\
\text { Long-Term Care } \\
(2018-2019)^{\mathrm{a}}\end{array}$ & $\begin{array}{l}\text { Experiencing Worsened } \\
\text { Pain in Long-Term Care } \\
(2018-2019)^{\mathrm{a}}\end{array}$ & $\begin{array}{l}\text { Other instruments } \\
\text { mandated that are not } \\
\text { specific to pain }\end{array}$ \\
\hline Alberta & No & Yes & $7.4 \%$ & $13.5 \%$ & $\begin{array}{l}\text { Long-Term Care } \\
\text { Accommodation Standards } \\
\text { and Checklist, } 2010 \\
\text { Continuing Care Health } \\
\text { Service Standards, } 2016\end{array}$ \\
\hline Saskatchewan & No & Yes & $9.0 \%$ & $11.8 \%$ & $\begin{array}{l}\text { Program Guidelines for } \\
\text { Special-care Homes, } 2016\end{array}$ \\
\hline Ontario & O. Reg. 79/10 & Yes & $5.2 \%$ & $9.7 \%$ & N/A \\
\hline
\end{tabular}

${ }^{a}$ Data obtained using CIHI's Your Health System interactive tool that provides recent interRAl indicator results [39]

and deals primarily with the physical standards around nursing homes. The second is the Continuing Care Health Service Standards [CCHSS], 2016 [42], set by Alberta Health's Continuing Care Branch. The CCHSS stipulate the minimum requirement that operators in the continuing care system must meet.

Within the residential care sector, the CCHSS apply to both LTC homes and publicly funded supportive living facilities, and pertain more to person-centered care planning, assessment, and case management. Pain management was mentioned under the operational processes in Standard 1.21 B (i.e., "Operational policies and processes shall include pain assessment and management") and is implemented and operationalized at the LTC facility level [42]. Subsection 1.0 (1.1) of the CCHSS mandates the use of the interRAI instruments by all operators (defined as those receiving public funding for the provision of health care) that are subject to the Nursing Home General Regulation. By incorporating the interRAI instruments, operators of LTC facilities must comply with all the requirements related to pain assessment and management contained therein.

\section{Saskatchewan}

In Saskatchewan, the overriding legislation for LTC facilities is the Provincial Health Authority Act which came into force in December 2017. The Housing and Specialcare Homes Regulations govern the administrative procedures under the Act, including nursing care (section 4), medications (section 8) and food services (section 11). The Facilities Designation Regulations under the Act describe the services to be provided by various health-related facilities in the province and section 12 states that a facility designated as a special-care home must provide personal care or nursing care to individuals who reside in the facility. Standard $1.4(\mathrm{u})$ of the guideline states "every effort is made to recognize, assess and appropriately manage pain". However, pain management protocol is left up to the discretion of the individual LTC facilities [82].
The provincial Ministry of Health publishes a manual entitled, Program Guidelines for Special-care Homes [Guidelines] [83], that was last updated in May 2016. Pursuant to the Facility Designation Regulations, section $17(2)$, all special-care homes are required to operate in accordance with the standards set out in the Guidelines. The quality indicators include assessing worsened pain. However, the Provincial Auditor's report noted that the measures tracked did not provide insight into the care practices (including pain management) of special-care homes [84].

The Guidelines provide detail regarding access to service; types of care to be provided; assessment procedures; requirements and qualifications of nursing and personal care providers; resident care plans; support services; and nutrition services. No specific references to pain in the statute or regulations were identified. However, the Guidelines incorporate (by virtue of Section 9a.1 Resident Assessment Tool) the interRAI suite, specifically RAI MDS 2.0, to all resident assessments.

\section{Ontario}

Ontario appears to be the only province where pain assessment or management directives are inserted directly into its regulations. The Long-Term Care Homes Act, 2007 is the governing statute in Ontario, furthered by General Regulation, O.R. 79/10. Ontario's General Regulation 79/10 refers to pain in terms of the plan of care (s.26), required programs (s.48), pain management (s.52), and training of direct care staff (s.221). The Ministry of Health and Long-Term Care is responsible for licensing, inspecting, and setting the fees for LTC homes [80]. Homes can be owned by private corporations, non-profit organizations, or municipal governments. In terms of the provision of care, the Act dictates that a plan of care be devised for each resident and prescribes the care services to be available in all LTC homes. The General Regulation provides further detail as to the requirements of the care plan and all nursing and support services. 
The General Regulation also makes specific reference to pain in several sections. With respect to the requirement for a plan of care for each resident, the regulation states (s.26) that the plan involve an interdisciplinary assessment of "health conditions, including allergies, pain, risk of falls and other special needs." Under required programs (s. 48), it stipulates that every home licensee have an interdisciplinary program in place that includes "a pain management program to identify pain in residents and manage pain." The specifics of these programs appear to be left to the responsibility of each LTC facility [80]. Finally, section 221 of the General Regulation requires that training of all staff who provide direct care to residents must include "pain management, including recognition of specific and nonspecific signs of pain."

Ontario's LTC homes are subject to the requirements of RAI-MDS 2.0, originally initiated in June 2005 [85]. RAI-MDS 2.0 has become the assessment tool for admission, quarterly and annual assessments, and significant changes in health status for each resident. According to the Ministry of Health and Long-Term Care's Guide to the Long-Term Care Homes Act [85], the interRAI suite derives its authority in Ontario from section 26(3) of the General Regulation, which specifies the domains of care that must be included in the assessment and is the basis of the plan of care.

\section{Discussion}

Several professional organizations are working to identify best practices and guidelines to support quality of pain assessment for LTC residents [40]. The Registered Nurses' Association of Ontario (2013), for example, released a report outlining best-practice guidelines for the assessment and management of pain [86]. Similarly, the Ontario Association of Non-Profit Homes and Services (2010) detailed a pain management approach [87]. Furthermore, accreditation standards for LTC facilities in Canada consider pain, but they have not succeeded in providing specific guidance about the use of cutting-edge assessment tools, especially for residents with limited ability to communicate. Despite these efforts, pain remains an unrecognized and undertreated condition in LTC settings [70, 88]. As such, leaving the specifics of quality improvement initiatives up to individual LTC facilities may be insufficient in addressing residents' pain. Of note, documented evidence suggests that LTC facilities face numerous barriers when attempting to successfully implement quality improvement initiatives [32, 33]. It is for this reason that this study was aimed at exploring another avenue in facilitating quality improvement initiatives. That is, the role of Canadian statutes and regulations in supporting pain assessment and management in LTC was examined through a panCanadian scoping review as well as an in-depth case analysis of Alberta, Saskatchewan, and Ontario.
Based on the illustrated example of Ontario's success in regulating LTC facilities, provincial government can use regulation as a vehicle to implement appropriate guidelines in LTCs. Specifically, provincial governments can proscribe specific standards and practices relative to pain assessment and management for LTC residents (e.g., increased frequency of pain assessments to match expert consensus guidelines [32]). Indeed, an examination of Ontario Regulation 79/10 under Ontario's Long-Term Care Homes Act illustrates the detail with which regulations of health standards can be extended, including the frequency of bathing (s.33), denture cleaning (s.34), and toenail cutting (s.35). As such, regulations in all provinces could require, on a compulsory basis, the three evidence-based pain assessment requirements set out in this policy review [32]. The use of regulations to implement these guidelines would be a far less onerous process than legislative changes and, furthermore, be more suited to defining the application of guidelines in adequate detail. In addition, while some cost to operators of LTC facilities in implementing these changes will be incurred, they are likely to be minimal as illustrated in prior implementation research [33].

The most important finding of this study is that, in the provinces of Alberta, Saskatchewan, and Ontario, interRAI is referenced as the legal standard for pain assessment and management as mandated by LTC regulations in each province. According to the interRAI website, all provinces except Quebec, New Brunswick, and Prince Edward Island have mandated the RAI-MDS 2.0 [89]. According to the Government of New Brunswick's website, New Brunswick also announced the adoption of the RAI assessment tool for use in nursing homes as of June 2015 [73]. The current mandated version for use in LTC facilities is the RAI-MDS 2.0. The Canadian Version of the RAI-MDS 2.0 User's Manual [90] addresses the issue of pain assessment and management. That is, the RAIMDS 2.0 includes an item to document pain frequency as "no pain," "pain present but not in the past 3 days," "present on 1 to 2 of the past 3 days," and "present daily in the past 3 days." Current pain intensity is documented as none, mild, moderate, severe, and unbearable. The pain frequency and intensity items can be summed to determine the Pain Scale score [91].

Although mandated by LTC regulations in most Canadian provinces, the RAI-MDS 2.0 still does not meet the recommended practice guidelines for pain assessment and management outlined at the beginning of this paper [32]. Of note, pain assessment is not the specific focus of the RAI-MDS or the suite of assessment tools [92-94]. The RAI-MDS 2.0 also does not require use of a standardized self-report tool such as a numeric rating scale or verbal-rating scale even though the use of clinical judgement in the absence 
of systematic specialized observation tools has been shown to result in pain being underdiagnosed [4-6, 12, 34]. Canada may be moving in that direction, however, as it is in the process of transitioning to the use of the interRAI Long-Term Care Facilities (LTCF) tool. The interRAI LTCF is an improvement from the RAI MDS 2.0 because it adds more information to the assessment process but still does not offer sufficient guidance for the optimization of pain assessments [95].

The use of the RAI-MDS may also lead to over- or under-reported pain $[79,80,85,96]$. For instance, facility characteristics have been shown to be more important than resident characteristics in predicting agreement between RAI-MDS pain indicators and a "gold standard" examination by nurse raters [97]. Moreover, Proctor and Hirdes (2001) showed that the RAI-MDS suggested a lower prevalence of identified pain among LTC residents with higher levels of cognitive impairment despite the absence of differences in the prevalence of pain-related conditions [98]. Importantly, current regulations in most Canadian provinces specify that pain assessment should be conducted at minimum once every 3 months using the RAI-MDS [41, 42]. From a clinical standpoint, however, this frequency of pain assessment is insufficient as it has been recommended that pain should be assessed at minimum once a week using specialized tools [99]. Even the more recent interRAI LTCF does not provide guidance on the frequency of pain assessments. Finally, residents who had limited ability to communicate-due to, for example, dementia-have been routinely excluded from studies examining the reliability and validity of the interRAI Pain Scale $[39,91,100]$. This is especially problematic given that over $25 \%$ of nursing home residents are unable to self-report pain and to comprehend questions related to pain assessment [1].

There is little question concerning the importance of maintaining a minimum data set for quality assurance purposes within the context of LTC. In Canada, the maintenance of a minimum data set has mostly been accomplished through the use of the RAI-MDS. Based on the limitations mentioned above, the quality of RAI-MDS pain assessments would, however, be enhanced through the use of specialized pain assessment tools (e.g., the Pain Assessment Checklist for Seniors with Limited Ability to Communicate-II (PACSLAC-II [101, 102]), the Pain Assessment in Advanced Dementia (PAINAD [103]), the Abbey Pain Scale [104] and others as recommended by pre-existing guidelines). In fact, the national Nursing Home Pain Collaborative in the United States has expressed the opinion that specialized pain assessment tools, such as the PACSLAC, would be especially useful for facilitating completion of the RAI-MDS [22, 99]. In their consensus article, Hadjistavropoulos and colleagues suggested that routine screening assessments involving standardized tools would typically require less than $5 \mathrm{~min}$ to complete $[32,105]$. This screening, of course, would be completed in addition to more comprehensive pain assessments undertaken at the time of admission or in other situations where it is clinically indicated. Once implemented, facilities could track pain levels over time and use these data as quality indicators to inform their quality improvement programs [32]. Therefore, one way of inciting further improvements in pain assessment and management might be regulatory changes mandating more frequent use of the RAI-MDS 2.0 in combination with one or more easy-to-administer standardized pain assessment tools [99].

Based on the findings of this study, future directions for research are proposed. First, the relationship between improved regulations and pain outcomes in the Canadian provincial context is warranted. Although this study's findings are suggestive of the need for regulatory changes to improve the assessment and management of pain in LTC, this relationship needs to be systematically investigated. Second, future research should examine the usefulness of mandating training for front-line LTC staff in the assessment and management of pain. This training, which can contribute to the enhancement of cutting-edge pain assessment and management knowledge, could be provided not only via traditional workshops but also through other media, such as video-based or online formats $[48,49]$. Such education is often necessary given that knowledge gaps among nursing staff are well-documented [106] and the specialized assessment of pain needed for residents with dementia is not yet provided in typical professional training programs for health professionals in Canada [21]. Third, our search strategy may have resulted in unidentified documents that could have informed the current scoping review. Future studies could involve either an environmental scan so as not to miss any relevant documents or a systematic review that would allow for a more comprehensive approach in identifying relevant documents. Furthermore, the exclusion of documents published in languages other than English may have resulted in limited input from the province of Québec, for which French is the official language, in this panCanadian review. Future studies should include, at minimum, documents in both English and French as these languages comprise Canada's official languages. Finally, research aimed at comparing the approach of Canadian jurisdictions to other international jurisdictions would be a valuable contribution to our overall understanding of pain assessment and management in LTC settings.

\section{Conclusions}

Policy interventions aimed at improving the quality of care can take a variety of forms, including regulatory 
requirements, carefully calibrated subsidies or other incentives to encourage certain behaviours, or accreditation requirements. From a policy perspective, constrained health budgets in the public sector put a premium on reducing the downstream cost of faulty diagnosis and treatment based on inadequate assessment and undermanagement of pain, a major problem among LTC residents with dementia. The policy remedy for this ailment is for governments to directly regulate reporting requirements for pain assessment and management. Addressing pain in LTC is an important avenue for policy work as significant discrepancies between current practices and internationally developed evidence-based clinical guidelines are noted. Improving the assessment and management of pain in LTC also fits within the broader goal of improving facility-based nursing care as well as the daily functioning and quality of life of LTC residents.

\section{Supplementary Information}

The online version contains supplementary material available at https://doi. org/10.1186/s12877-020-01758-7

Additional file 1: Appendix A. 10-province scan of LTC statutes and regulations. This additional file includes an appendix describing our results from a scan of long-term care statutes and regulations across the 10 Canadian provinces.

\section{Abbreviations}

CCHSS: Continuing Care Health Service Standards; CAPs: Clinical Assessment Protocols; Guidelines: Program Guidelines for Special-care Homes; LHINs: Local Health Integration Networks; LTC: Long-term care; L-SAA: LongTerm Care Home Service Accountability Agreement; PACSLAC-II: Pain Assessment Checklist for Seniors with Limited Ability to Communicate-II; PAINAD: Pain Assessment in Advanced Dementia; RAI-MDS: Resident Assessment Instrument-Minimum Data Set

\section{Acknowledgments}

Not applicable.

\section{Authors' contributions}

GM and TH led the conceptualization with support from BR. Methodology and data collection were completed by AP, BR, and NG. The data analysis and write-up of the results was completed by BR, NG, AP, and RS. Write up and review of the manuscript was completed by GM, TH, BR, AP, and NG. All authors have read and approved the manuscript.

\section{Funding}

AGEWELL WP 6.2. No financial interest or benefit has arisen from the direct applications of this research.

\section{Availability of data and materials}

Only publicly available documents were analyzed for this research. No other data was used.

Ethics approval and consent to participate

Not Applicable-No participants were recruited, and no human data were collected for this study.

\section{Consent for publication}

Not applicable.

\section{Competing interests}

The authors have no competing interests to declare.

\section{Author details}

'Department of Psychology and Center on Aging and Health, University of Regina, 3737 Wascana Parkway, Regina, Saskatchewan S4S OA2, Canada. ${ }^{2}$ Edson College of Nursing and Health Innovation, Arizona State University, 550 N 3rd Street, Phoenix, AZ 85004, USA. Institute of Health Policy, Management and Evaluation, University of Toronto, 425-155 College Street, Toronto, Ontario M5T 3M6, Canada.

Received: 20 February 2020 Accepted: 8 September 2020

Published online: 09 November 2020

\section{References}

1. Ferrell BA, Ferrell BR, Rivera L. Pain in cognitively impaired nursing home patients. J Pain Symptom Manag. 1995;10(8):591-8.

2. Abdulla A, Adams N, Bone M, Elliott AM, Gaffin J, Jones D, Knaggs R, Martin D, Sampson L, Schofield P. Guidance on the management of pain in older people. Age Ageing. 2013;42:i1-i57.

3. Ferrell BA. Pain evaluation and management in the nursing home. Ann Intern Med. 1995;123(9):681-7.

4. Cowan DT, Fitzpatrick JM, Roberts JD, While AE, Baldwin J. The assessment and management of pain among older people in care homes: current status and future directions. Int J Nurs Stud. 2003;40(3):291-8.

5. Sengstaken EA, King SA. The problems of pain and its detection among geriatric nursing home residents. J Am Geriatr Soc. 1993;41(5):541-4.

6. Hadjistavropoulos T, Kaasalainen S, Williams J, Zacharias R. Improving pain assessment practices and outcomes in long-term care facilities: a mixed methods investigation. Pain Manag Nurs. 2014;15(4):748-59.

7. Hanlon JT, Wang X, Castle NG, Stone RA, Handler SM, Semla TP, Pugh MJ, Berlowitz DR, Dysken MW. Potential underuse, overuse, and inappropriate use of antidepressants in older veteran nursing home residents. J Am Geriatr Soc. 2011;59(8):1412-20.

8. Martin R, Williams J, Hadjistavropoulos T, Hadjistavropoulos HD, MacLean M. A qualitative investigation of seniors' and caregivers' views on pain assessment and management. Can J Nurs Res. 2005;37(2):142-65.

9. Kaasalainen S, Middleton J, Knezacek S, Hartley T, Stewart N, Ife C, Robinson L. Pain and cognitive status in the institutionalized elderly. J Gerontol Nurs. 1998;24(8):24-31.

10. Zwakhalen SMG, Hamers JPH, Abu-Saad HH, Berger MPF. Pain in elderly people with severe dementia: A systematic review of behavioural pain assessment tools. BMC Geriatr. 2006;6:Article 3.

11. Scherder E, Oosterman J, Swaab D, Herr K, Ooms M, Ribbe M, Segeant J, Pickering G, Benedetti F. Recent developments in pain in dementia. Br Med J. 2005;330:461-4.

12. Bauer U, Pitzer S, Schreier MM, Osterbrink J, Alzner R, Iglseder B. Pain treatment for nursing home residents differs according to cognitive state-a cross-sectional study. BMC Geriatr. 2016;16(1):124.

13. McAuliffe L, Nay R, O'Donnell M, Fetherstonhaugh D. Pain assessment in older people with dementia: literature review. J Adv Nurs. 2009;65(1):2-10.

14. AGS Panel on Persistent Pain in Older Persons. The management of persistent pain in older persons. J Am Geriatr Soc. 2002;50(6 suppl):S205-24.

15. Parmelee PA, Katz IR, Lawton MP. The relation of pain to depression among institutionalized aged. J Gerontol. 1991:46(1):15-21.

16. Juurlink DN, Herrmann N, Szalai JP, Kopp A, Redelmeier DA. Medical illness and the risk of suicide in the elderly. Arch Intern Med. 2004;164(11):1179-84.

17. Vohra JU, Brazil K, Hanna S, Abelson J. Family perceptions of end-of-life care in long-term care facilities. J Palliat Care. 2004;20(4):297-302.

18. Organization for Economic Co-operation and Development. Ensuring quality long-term care for older people. OECD Observer. 2005:1-8.

19. Achterberg WP, Pieper MJ, van Dalen-Kok AH, de Waal MW, Husebo BS, Lautenbacher S, Kunz M, Scherder EJ, Corbett A. Pain management in patients with dementia. Clin Inter Aging. 2013;8:1471-82.

20. Achterberg W. Pain management in long-term care: are we finally on the right track? Age Ageing. 2016;45(1):7-8

21. Watt-Watson J, Peter E, Clark AJ, Dewar A, Hadjistavropoulos T, MorleyForster P, O'Leary C, Raman-Wilms L, Unruh A, Webber K, Campbell-Yeo M. The ethics of Canadian entry-to-practice pain competencies: how are we doing? Pain Res Manag. 2013;13:25-32.

22. Herr K, Bursch H, Ersek M, Miller LL, Swafford K. Use of pain-behavioral assessment tools in the nursing home: expert consensus recommendations for practice. J Gerontol Nurs. 2010;36(3):18-29. 
23. Hadjistavropoulos T, Fitzgerald TD, Marchildon GP. Practice guidelines for assessing pain in older persons with dementia residing in long-term care facilities. Physiother Can. 2010;62(2):104-13.

24. American Geriatrics Society Panel on the Pharmacological Management of Persistent Pain in Older Persons. Pharmacological management of persistent pain in older persons. J Am Geriatr Soc. 2009;57:1331-46.

25. Australian Pain Society. Pain in residential aged care facilities: management strategies. North Sydney, Australia: Australian Pain Society; 2005.

26. Schofield P. The assessment of pain in older people: UK national guidelines. Age Ageing. 2018;47:i1-i22.

27. Hadjistavropoulos T, LaChapelle DL, Hadjistavropoulos HD, Green S, Asmundson GJG. Using facial expressions to assess musculoskeletal pain in older persons. Eur J Pain. 2002;6:179-87.

28. Herr K, Coyne PJ, McCaffery M, Manworren R, Merkel S. Pain assessment in the patient unable to self-report: position statement with clinical practice recommendations. Pain Manag Nurs. 2011;12(4):230-50.

29. Corbett A, Achterberg W, Husebo B, Lobbezo F, de Vet H, Kunz M, Constantinou M, Tudose C, Kappesser J, de Waal M, Lautenbacher S. An international road map to improve pain assessment in people with impaired cognition: the development of the Pain Assessment in Impaired Cognition (PAIC) meta-tool. BMC Neurol. 2014;14:229.

30. Hadjistavropoulos T, Herr K, Prkachin K, Craig K, Gibson S, Lukas L, Smith J. Pain assessment in elderly adults with dementia. Lancet Neurol. 2014;13:1216-27.

31. Herr K, Coyne PJ, Ely E, Gélinas C, Manworren RCB. Pain assessment in the patient unable to self-report: clinical practice recommendations in support of the ASPMN 2019 position statement. Pain Manag Nurs. 2019;20(5):404-17.

32. Hadjistavropoulos T, Janzen Claude JA, Hadjistavropoulos HD, Marchildon GP, Kaasalainen S, Gallagher R, Beattie BL. Stakeholder opinions on a transformational model of pain management in long-term care. J Gerontol Nurs. 2011:37:40-51

33. Hadjistavropoulos T, Williams J, Kaasalainen S, Hunter PV, Savoie ML, Wickson-Griffiths A. Increasing the frequency and timeliness of pain assessment and management in long-term care: knowledge transfer and sustained implementation. Pain Res Manag. 2016;2016:6493463.

34. Fuchs-Lacelle S, Hadjistavropoulos T, Lix L. Pain assessment as intervention: a study of older adults with severe dementia. Clin J Pain. 2008;24(8):697-707.

35. Rovner BW, Edelman BA, Cox MP, Schmuely Y. The impact of antipsychotic drug regulations on psychotropic prescribing practices in nursing homes. Am J Psychiatry. 1992;149:1390-2.

36. Semla TP, Palla K, Poddig B, Brauner DJ. Effect of the omnibus reconciliation act 1987 on antipsychotic prescribing in nursing home residents. J Am Geriatr Soc. 1994;42:648-52.

37. Shorr Rl, Fought RL, Ray WA. Changes in antipsychotic drug use in nursing homes during implementation of the OBRA-87 regulations. JAMA. 1994;271: 358-62.

38. Howlett M. Policy tools and their role in policy formulation: dealing with procedural and substantive instruments. In: Howlett M, Mukherjee I, editors. Handbook of policy formulation. Cheltenham: Edward Elgar; 2017. p. 96-111.

39. Your Health Systems: In Depth. Ottawa, ON: Canadian Institute of Health Information. https://yourhealthsystem.cihi.ca/hsp/indepth?lang=en\#/. Accessed 09 July 2020

40. Estabrooks CA, Poss JW, Squires JE, Teare GF, Morgan DG, Stewart N, Doupe $M B$, Cummings GG, Norton PG. A profile of residents in prairie nursing homes. Can J Aging. 2013;32(3):223-31.

41. Government of Alberta. Long-term care accommodation standards and checklist. Edmonton: Alberta Health; 2010.

42. Government of Alberta. Continuing care health service standards. Edmonton: Alberta Health; 2018.

43. Carpenter I, Hirdes JP. Using interRAl assessment systems to measure and maintain quality of long-term care. In OECD/European Commission, editors. A good life in old age? Monitoring and improving quality in long-term care. Paris: OECD Publishing; 2013.

44. Arksey H, O'Malley L. Scoping studies: towards a methodological framework. Int J Soc Res Methodol. 2005;8(1):19-32.

45. Colquhoun HL, Levac D, O'Brien KK, Straus S, Tricco AC, Perrier L, Kastner M, Moder D. Scoping reviews: time for clarity in definition, methods, and reporting. J Clin Epidemiol. 2014;67(12):1291-4.

46. Bainbridge $D$, Seow H. Palliative care experience in the last 3 months of life: a quantitative comparison of care provided in residential hospices, hospitals and the home from the perspectives of bereaved caregivers. Am J Hosp Palliat Me. 2018;35(3):456-63.
47. Cheung ENM, Benjamin S, Heckman G, Ho JM-W, Lee L, Sinha SK, Costa AP. Clinical characteristics associated with the onset of delirium among longterm care nursing home residents. BMC Geriatr. 2018;18(39):1-7.

48. Gagnon MM, Hadjistavropoulos T, Williams J. Development and mixedmethods evaluation of a pain assessment video training program for longterm care staff. Pain Res Manag. 2013;18(6):307-12.

49. Ghandehari OO, Hadjistavropoulos T, Williams J, Thorpe L, Alfano DP, BelloHaas VD, Malloy DC, Martin RR, Rahaman O, Zwakhalen SM, et al. A controlled investigation of continuing pain education for long-term care staff. Pain Res Manag. 2013;18(1):11-8.

50. Helmer-Smith M, Fung C, Afkham A, Crowe L, Gazarin M, Keely E, Moroz I, Liddy C. The feasibility of using electronic consultation in long-term care homes. J Am Med Dir Assoc. 2020;21(8):1166-70.

51. Hirdes JP, Mitchell L, Maxwell CJ, White N. Beyond the 'iron lungs of gerontology': using evidence to shape the future of nursing homes in Canada. Can J Aging. 2011;30(3):371-90.

52. Hunter PV, McCleary L, Akhtar-Danesh N, Goodridge D, Hadjistavropoulos T, Kaasalainen S, Sussman T, Thompson G, Venturato L, Wickson-Griffiths A. Mind the gap: is the Canadian long-term care workforce ready for a palliative care mandate? Ageing Soc. 2020;40:1223-43.

53. Kaasalainen $\mathrm{S}$, Brazil $\mathrm{K}$, Coker E, Ploeg J, Martin-Milsener R, Donald F, DiCenso A, Hadjistavropoulos T, Dolovich L, Papaioannou A, Emili A, Burns T. An action-based approach to improving pain management in long-term care. Can J Aging. 2010;29(4):503-17.

54. Kaasalainen S, Wickson-Griffiths A, Akhtar-Danesh N, Brazil K, Donald F, Martin-Misener R, DiCenso A, Hadjistavropoulos T, Dolovich L. The effectiveness of a nurse practitioner-led pain management team in longterm care: a mixed methods study. Int J Nurs. 2016;62:156-67.

55. Lane NE, Stukel TA, Boyd CM, Wodchis WP. Long-term care residents' geriatric syndromes at admission and disablement over time: an observational cohort study. J Gerontol A Biol Sci Med Sci. 2019;74(6):917-23.

56. Mashouri $P$, Taati $B$, Quirt $H$, laboni A. Quality indicators as predictors of future inspection performance in Ontario nursing homes. JAMDA. 2020;21: 793-8.

57. McArthur C, Saari M, Northwood M, Taucar LS, Boscart VM. Profiling the characteristics of people who are comatose in long-term and complex continuing care settings. JAMDA. 2019;20:1331-4.

58. McCleary L, Thompson GN, Venturato L, Wickson-Griffiths A, Hunter P, Sussman T, Kaasalainen S. Meaninful connections in dementia end of life care in long term care homes. BMC Psychiatry. 2018;18:307.

59. Nemiroff L, Marshall EG, Jensen JL, Clarke B, Andrew MK. Adherence to "no transfer to hospital" advance directives among nursing home residents. J Am Med Dir Assoc. 2019;20:1373-81.

60. Ramage-Morin PL. Chronic pain in Canadian seniors. Health Rep. 2008;19(1): $37-52$.

61. Rosenberg T, Montgomery $\mathrm{P}$, Hay $\mathrm{V}$, Lattimer R. Using frailty and quality of life measures in clinical care of the elderly in Canada to predict death, nursing home transfer and hospitalisation - the frailty and ageing cohort study. BMJ Open. 2019;9:e032712.

62. Senderovich H, Grewal J, Mujtaba M. Herpes zoster cavvination efficacy in long-term care facility population: A qualitative systematic review. Curr Med Res Opin. 2019;35(8):1451-62.

63. Tadrous M, Fung K, Desveaux L, Gomes T, Taljaard M, Grimshaw JM, Bell CM, Ivers NM. Effect of academic detailing on promoting appropriate prescribing of antipsychotic medication in nursing homes: a cluster randomized clinical trial. JAMA Netw Open. 2020;3(5):e205724.

64. Turcotte LA, Marrie RA, Patten SB, Hirdes JP. Clinical profile of persons with multiple sclerosis across the continuum of care. Can J Neurol Sci. 2018;45: 188-98.

65. Wilchesky M, Mueller G, Morin M, Marcote M, Voyer P, Aubin M, Carmichael $\mathrm{P}-\mathrm{H}$, Champoux N, monette J, Giguère A, Durand P, Verreault $\mathrm{R}$, Arcand $\mathrm{M}$, Kröger $E$. The OptimaMed intervention to reduce inappropriate medications in nursing home residents with severe dementia: results from a quasiexperimental feasibility pilot study. BMC Geriatr. 2018;18:204.

66. Wilkinson A, Haroun V, Wong T, Cooper N, Chignell M. Overall quality performance of long-term care homes in Ontario. Healthc Q. 2019;22(2):55-62.

67. Yoon MN, Ickert C, Slaughter SE, Lengyel C, Carrier N, Keller H. Oral health status of long-term care residents in Canada: results of a national crosssectional study. Gerodontology. 2018;35:359-64.

68. Yoon MN, Lu L, Ickert C, Estabrooks CA, Hoben M. If we cannot measure it, we cannot improve it: Understanding measurement problems in routine 
oral/dental assessments in Canadian nursing homes. Gerodontology. 2020; 37:164-76.

69. Yu AYX, Maclagan LC, Diong C, Austin PC, Kapral MK, Swartz RH, Bronskill SE. Sex differences in care need and survival in patients admitted to nursing home poststroke. Can J Neurol Sci. 2020;47:153-9.

70. Fitzgerald C. RAI-MDS guidelines and FAM. London: Western University's Canadian Centre for Activity and Aging; 2016.

71. Hill C, Duggleby W, Venturato L, Durepos P, Kulasegaram P, Hunter P, McCleary L, Sussman T, Thompson G, Surtees D, Wickson-Griffiths A, Kaasalainen $\mathrm{S}$. An analysis of documents guiding palliative care in five Canadian provinces. CJA. 2019;38(3):281-95.

72. Government of Newfoundland and Labrador. Long Term Care Facilities in Newfoundland and Labrador: Operational Standards. St. John's: Newfoundland and Labrador Department of Health and Community Services; 2005

73. Government of New Brunswick. Standards manual: nursing home services. Fredericton: Department of Social Development; 2019.

74. Government of Nova Scotia. Long term care program requirements: nursing homes \& residential care facilities. Halifax: Health \& Wellness; 2019

75. Government of British Columbia. Home and community care policy manual: long-term care services. Vancouver: Ministry of Health; 2019.

76. Government of Manitoba. The health services insurance act: personal care homes standards regulation. Winnipeg: Ministry of Health; 2020

77. Government of Prince Edward Island. Community care facilities and nursing homes act. Charlottetown: Legislative Counsel Office; 2019

78. Castle NG, Ferguson JC. What is nursing home quality and how is it measured? Gerontologist. 2010;50(4):426-42

79. Fisher SE, Burgio LD, Thorn BE, Allen-Burge R, Gerstle J, Roth DL, Allen SJ. J Am Geriatr Soc. 2002;50(1):152-6.

80. Government of Ontario. Home, community and residential care services: long-term care home service accountability agreement. Toronto: Ministry of Health and Long-Term Care; 2019.

81. Choiniere JA, Doupe M, Goldmann M, Harrington C, Jacobsen FF, Llyod L, Rootham M, Szebehely M. Mapping nursing home inspections \& audits in six countries. Ageing Int. 2016;41(1):40-61.

82. Ombudsman Saskatchewan. Taking care: an ombudsman investigation into the care provided to Margaret Warholm while a resident of the Santa Maria senior citizens home. Regina: Ombudsman Saskatchewan; 2015.

83. Government of Saskatchewan. Special care-home program guidelines manual. Regina: Ministry of Health; 2016.

84. Provincial Auditor of Saskatchewan. Saskatoon Regional Health Authority_-Overseeing Contracted Special-Care Homes. Regina: Provincial Auditor of Saskatchewan; 2017:161-180.

85. Government of Ontario. Guide to the long-term care homes act, 2007 and regulation 79/10. Toronto: Ministry of Health and Long-Term Care; 2011.

86. Registered Nurses' Association of Ontario. Assessment and Management of Pain. Toronto: Registered Nurses' Association of Ontario; 2013.

87. Ontario Association of Non-Profit Homes \& Services for Seniors. Pain management program policy, procedures, and training package. Woodbridge: Ontario Association of Non-Profit Homes \& Services for Seniors; 2010

88. Reid MC, O'Neil KW, Dancy J, Berry CA, Stowell SA. Pain management in long-term care communities: a quality improvement initiative. J Am Med Dir Assoc. 2015;23(2):29-35.

89. interRAl Canada. Welcome to interRAl Canada. https://uwaterloo.ca/interraicanada/. Accessed 09 July 2020.

90. Resident Assessment Instrument-Minimum Data Set (RAl-MDS) User's Manual 2.0 (Canadian version). Washington, DC: interRAl; 2012.

91. Fries BE, Simon SE, Morris JN, Flodstrom C, Bookstein FL. Pain in U.S. nursing homes: Validating a pain scale for the minimum data set. Gerontologist. 2001:41:173-9.

92. Lukas A, Mayer B, Fiavolá D, Topinkova E, Gindin J, Onder G, Bernabei R, Nikolaus T, Denkinger MD. Pain characteristics and pain control in European nursing homes: cross-sectional and longitudinal results from the services and health for elderly in long TERm care (SHELTER) study. J Am Med Dir Assoc. 2013;14:421-8.

93. Lukas A, Mayer B, Fiavolá D, Topinkova E, Gindin J, Onder G, Bernabei R, Nikolaus T, Denkinger MD. Treatment of pain in European nursing homes: results from the services and health for elderly in long TERm care (SHELTER) study. J Am Med Dir Assoc. 2013;14:821-31.
94. Tosato M, Lukas A, van der Roest HG, Danese P, Antocicco M, Finne-Soveri H, Nikolaus T, Landi F, Bernabei R, Onder G. Association of pain with behavioral and psychiatric symptoms among nursing home residents with cognitive impairment: results from the SHELTER study. Pain. 2012;153:305-10.

95. Morris JN, Berg K, Björkgren M, Costa AP, Declerq A, Finne-Soveri UH, Fries BE, Frijters D, Gray L, Head MJ, Heckman G, Henrard J-C, Hirdes JP, James ML, Ljunggren G, Meehan B, Stewart SL, Szczerbinska K, \& Topinková E. interRAl long-term care facilities (LTCF) assessment form and User's manual (version 10.0, interRAl standard edition). Washington, DC: interRAl.

96. Cohen-Mansfield J. The adequacy of the minimum data set assessment of pain in cognitively impaired nursing home residents. J Pain Symptom Manag. 2004;27(4):343-51.

97. Wu N, Miller SC, Lapane K, Roy J, Mor V. The quality of the quality indicator of pain derived from the minimum data set. Health Serv Res. 2005;40(4): 1197-216.

98. Proctor WR, Hirdes JP. Pain and cognitive status among nursing home residents in Canada. Pain Res Manag. 2001;6(3):119-25.

99. Hadjistavropoulos T, Marchildon GP, Fine PG, Herr K, Palley HA, Kaasalainen $S$, Béland F. Transforming long-term care pain management in North America: the policy-clinical interface. Pain Med. 2009;10(3):506-20.

100. Cadogan MP, Schnelle JF, Yamamoto-Mitani N, Cabrera G, Simmons SF. A minimum data set prevalence of pain quality indicator: is it accurate and does it reflect differences in care processes? J Gerontol A Biol Sci Med Sci. 2004;59(3):M281-5.

101. Fuchs-Lacelle S, Hadjistavropoulos T. Development and preliminary validation of the pain assessment checklist for seniors with limited ability to communicate (PACSLAC). Pain Manag Nurs. 2004;5:37-49.

102. Chan S, Hadjistavropoulos T. Evidence-based development and initial validation of the pain assessment checklist for seniors with limited ability to communicate-II (PACSLAC-II). Proceedings of the Canadian Pain Society's annual conference; 2013; Toronto. ON.

103. Warden V, Hurley AC, Volicer V. Development and psychometric evaluation of the pain assessment in advanced dementia (PAINAD) scale. J Am Med Dir Assoc. 2003:4:9-15.

104. Abbey J, Piller N, De Bellis A, Esterman A, Parker D, Giles L, Lowcay B. The Abbey pain scale: a 1-minute numerical indicator for people with end-stage dementia. Int J Palliat Nurs. 2004;10(1):6-13.

105. Hadjistavropoulos T, Herr K, Turk DC, Fine PG, Dworkin RH, Helme R, Jackson K, Parmelee PA, Rudy TE, Beattie BL, Chibnall JT, Craig KD, Ferrell B, Ferrell B, Fillingim RB, Gagliese L, Gallagher R, Gibson SG, Harisson L, Katz B, Keefe F, Lieber SJ, Lussier D, Schmader KE, Tait RC, Weiner DK, Williams J. An interdisciplinary expert consensus statement on assessment of pain in older persons. Clin J Pain. 2007;23:S1-S43.

106. Zwakhalen SMG, Hamers JPH, Peijnenburg RHA, Berger MPF. Nursing staff knowledge and beliefs about pain in elderly nursing home residents with dementia. Pain Res Manag. 2007;12(3):177-84.

\section{Publisher's Note}

Springer Nature remains neutral with regard to jurisdictional claims in published maps and institutional affiliations.

Ready to submit your research? Choose BMC and benefit from:

- fast, convenient online submission

- thorough peer review by experienced researchers in your field

- rapid publication on acceptance

- support for research data, including large and complex data types

- gold Open Access which fosters wider collaboration and increased citations

- maximum visibility for your research: over $100 \mathrm{M}$ website views per year

At BMC, research is always in progress.

Learn more biomedcentral.com/submissions 